\title{
Improvement of a suction air cooling method for combined cycle power plants using water spray and its application to working plants
}

\author{
Shuichi UMEZAWA* and Katsuhiko SUGITA** \\ *TEPCO Research Institute, Tokyo Electric Power Company Holdings, Inc. \\ 4-1, Egasaki-cho, Tsurumi-ku, Yokohama 230-8510, Japan \\ E-mail: umezawa.s@tepco.co.jp \\ **TEPCO Research Institute, Tokyo Electric Power Company Holdings, Inc. \\ 4-1, Egasaki-cho, Tsurumi-ku, Yokohama 230-8510, Japan
}

Received 20 May 2016

\begin{abstract}
Output increase of combined cycle power plants is highly expected in order to deal with tight supply-demand situation of electricity and to save fuel consumption. This paper reports improvement of the output increase method by cooling their suction air using water spray nozzles. The spray nozzles installed previously are pointing to downstream of air flow or downward. We tried to improve its cooling efficiency by optimizing the spray nozzle angle. Laboratory experiments were conducted for that purpose. Suction air area was 2 meter square, and air flow velocity was set to approximately 2 meter/sec. by a blower. Temperature and relative humidity were set to 33 degrees centigrade and 60 percent respectively by air-conditioning units. As a result, a method that the spray nozzles are pointing upstream of air flow showed the best performance. The same tendency was also observed by finite volume analysis using a CFD program. This method was applied at both a working combined cycle power plant of $380 \mathrm{MW}$ and that of $500 \mathrm{MW}$ on trial. Temperature of cooled air was measured using a number of thermocouples set in suction air room at each plant. Consequently, it was observed that the cooling efficiency was improved by ten percent and several percent respectively, and plant output was increased by approximately $2 \mathrm{MW}$ at the $380 \mathrm{MW}$ plant.
\end{abstract}

Key words: Gas turbine, Combined cycle, Output increase, Suction air cooling, Water spray, Nozzle

\section{Introduction}

Almost all of nuclear power plants are still out of operation in Japan after the 2011 east Japan earthquake and tsunami disaster. Accordingly, supply-demand situation of electricity became very tight, and fossil fuel consumption was increased to secure electricity supply. They are social important issues to be solved in Japan.

Our thermal power stations have taken measures such as urgent installation of power supply systems, shorting scheduled inspection period, output increase of conventional thermal plants by the method of feed water bypassing feed water heaters (Umezawa 2013, 2014), output increase of combined cycle power plants by cooling their suction air using water spray nozzles (Umezawa and Tanaka 2014). The suction air cooling is especially remarkable among them, because it is highly effective in summer season when supply-demand situation of electricity becomes tight and because it can save fuel consumption by decreasing the operation rate of low-efficiency thermal power plants.

Air cooling system by water spray was previously installed to a upstream position of air filter at almost all of our combined cycle power plants because it was pointed out that compressor blades was tend to be eroded in the case that spray system was installed to a downstream position of air filter (Kahn, et al., 2012). Then the spray nozzles were set pointing to downstream of air flow or downward in convention. We tried to improve its cooling efficiency by optimize 
the internal structure of spray nozzle and spray nozzle angle. Laboratory experiments were carried out for that purpose. Furthermore finite volume analysis using a CFD program was also conducted in order to confirm the laboratory experiment results. The improved spray method which was found by the laboratory experiments and the CFD analysis was examined at both a working combined cycle power plant of $380 \mathrm{MW}$ and that of $500 \mathrm{MW}$ on trial. Temperature of cooled air was measured using a number of thermocouples set in suction air room, which is located at a downstream position of the water spray, in order to obtain the cooling efficiency at each plant.

\section{Nomenclature}

Symbols

A:Surface area $\left[\mathrm{m}^{2}\right]$

h: Convective heat transfer coefficient $\left[\mathrm{W} / \mathrm{m}^{2} \cdot{ }^{\circ} \mathrm{C}\right]$

m: Mass [kg]

$\mathrm{t}$ : Time [s]

Subscripts

Atm: Atmospheric

P: Water particle

$\infty$ : Continuous phase

\author{
$\mathrm{C}$ : Specific heat $\left[\mathrm{J} / \mathrm{kg} \cdot{ }^{\circ} \mathrm{C}\right]$ \\ $\mathrm{h}_{\mathrm{fg}}$ : Latent heat $[\mathrm{J} / \mathrm{kg}]$ \\ $\mathrm{T}$ : Temperature $\left[{ }^{\circ} \mathrm{C}\right]$ \\ $\eta$ : Cooling efficiency [-]
}

Cooled: Cooled air

WB: Wet bulb

\section{Laboratory experiments \\ 2.1 Experimental apparatus}

Laboratory experiments were conducted for the purpose of improving suction air cooling efficiency. The outlook of experimental apparatus is shown in Fig.1. A suction air area was 2 meter square, in which a set of weather louvers having vertical slits was installed. Eighty-one pieces of thermocouples were set at the position of $0.6 \mathrm{~m}$ downstream from the louvers, with grating a pattern of nine pieces in vertical direction and nine pieces in horizontal direction. That is to say each distance between one thermocouple and the next is 0.2 meter. Air flow velocity could be set to $2.5 \mathrm{~m} / \mathrm{s}$ at the maximum by a blower, which was located at a downstream position of the thermocouples. Temperature and relative humidity were set to 33 degrees centigrade and 60 percent respectively by air-conditioning units.

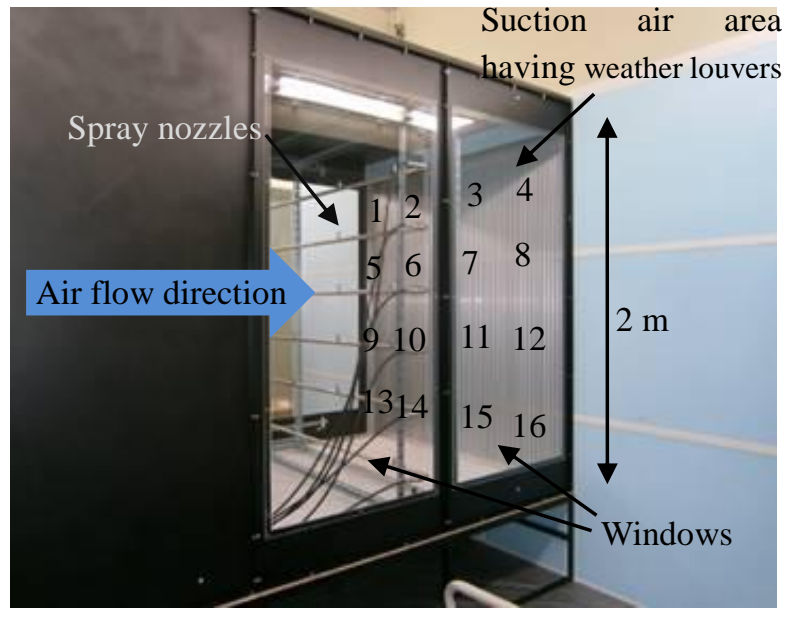

Fig. 1 Outlook of the experimental apparatus

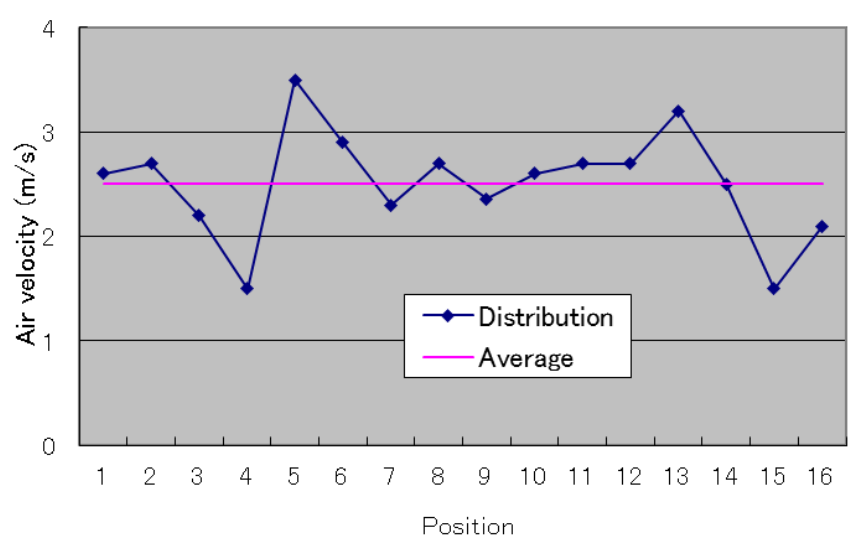

Fig. 2 Distribution of air velocity across the air flow at suction air area

Distribution of air velocity across the air flow at the suction air area is shown in Fig. 2. The horizontal axis represents positions of the suction air area, which was divided to sixteen areas with a grating pattern of four areas in vertical direction and four areas in horizontal direction, as shown in Fig.1. The air velocity was measured at a center of each area by hot wire velocity meter, Kanomax Japan Inc. model 6034, for one minute. Then, averaged velocity was calculated by averaging each area's velocity. Inside structure of the duct at a downstream of the suction air area was adjusted so that the distribution was as uniform as possible by setting obstacles in the way of higher velocity. A wind 
tunnel was set at an upstream position of the suction air area. The size of the tunnel is $2.17 \mathrm{~m}$ in height of a cross section, $2.08 \mathrm{~m}$ in width of that and $2.9 \mathrm{~m}$ in depth. The spray nozzles were set in the wind tunnel. The distance between the spray nozzles and the suction air area was adjustable in the range between $0.5 \mathrm{~m}$ and $2.65 \mathrm{~m}$. Nozzle angle was set in the range between 0 degree and 360 degrees.

Specifications of two kinds of spray nozzles used in the present experiment are shown in Table 1. Both nozzles are used at working plants. Spray form of type A nozzle, as shown in Fig. 3, is full cone. And that of type B is flat sector. Both type of nozzle are very different in the way of spray flow rate and diameter of spray particle. The diameter and velocity of spray particle were measured by a Phase Laser Doppler Interferometer, as shown in Fig. 4. The diameter is Sauter mean one and the velocity is average one of each spray particle.

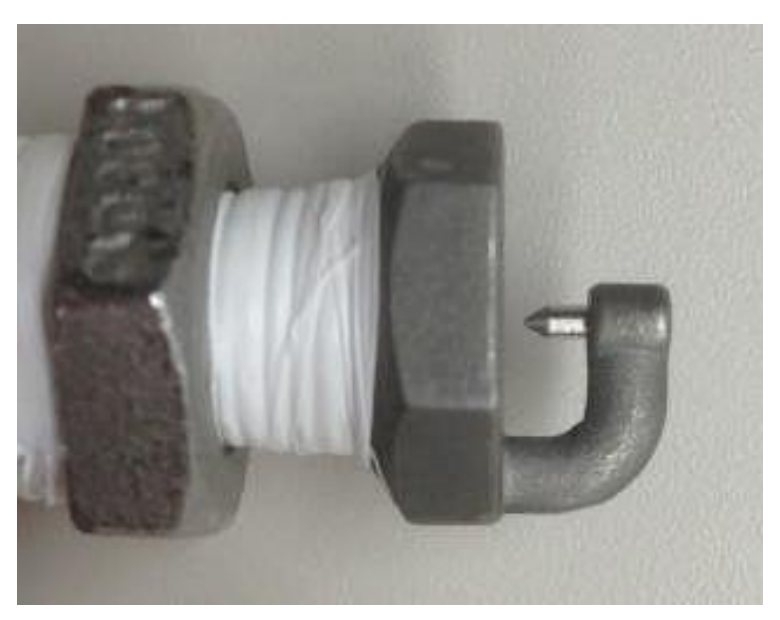

Fig. 3 Type A nozzle

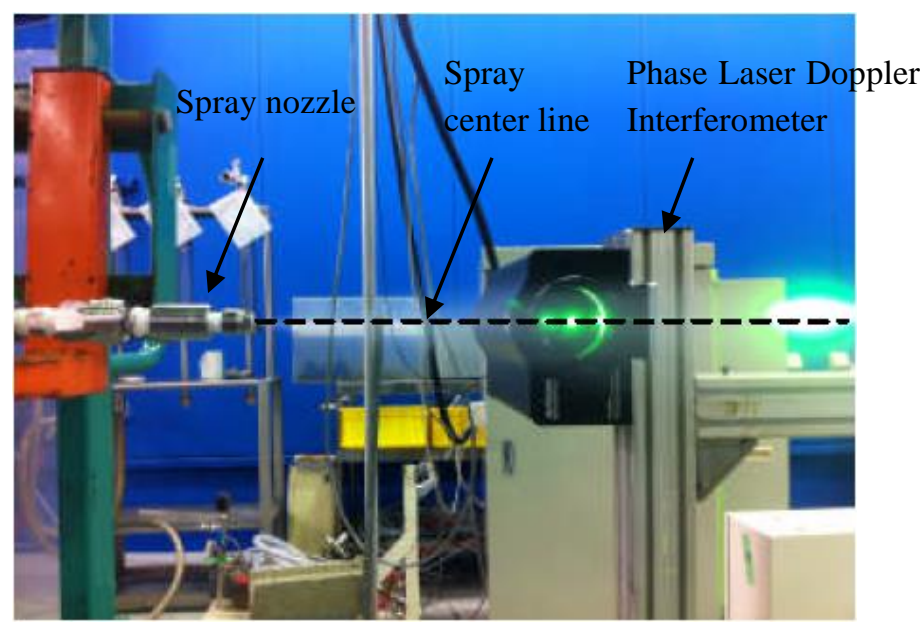

Fig. 4 Phase Laser Doppler Interferometer

Table 1 Specifications of spray nozzles.

\begin{tabular}{|c|c|c|c|}
\hline \multicolumn{2}{|l|}{ Nozzle } & A & $\mathrm{B}$ \\
\hline \multicolumn{2}{|l|}{ Spray form } & Full cone & Flat sector \\
\hline \multicolumn{2}{|c|}{ Spray pressure $[\mathrm{MPa}]$} & 6.0 & 6.0 \\
\hline \multicolumn{2}{|c|}{ Spray flow rate [L/min] } & 0.200 & 1.88 \\
\hline \multicolumn{2}{|c|}{ Spray angle [deg.] } & 75 & 119 \\
\hline \multicolumn{2}{|c|}{ Spray size at a distance of $300 \mathrm{~mm}[\mathrm{~mm}]$} & Width: $270 \times$ Height: 220 & Width: $650 \times$ Height: 80 \\
\hline \multicolumn{2}{|c|}{ Spray size at a distance of $500 \mathrm{~mm}[\mathrm{~mm}]$} & Width: $460 \times$ Height: 310 & Width: $800 \times$ Height: 120 \\
\hline \multirow{2}{*}{ Particles at a distance of $300 \mathrm{~mm}$} & Diameter $[\mu \mathrm{m}]$ & 37.7 & 70.5 \\
\hline & Velocity $[\mathrm{m} / \mathrm{s}]$ & 4.4 & 19.1 \\
\hline \multirow{2}{*}{ Particles at a distance of $500 \mathrm{~mm}$} & Diameter $[\mu \mathrm{m}]$ & 43.2 & 89.6 \\
\hline & Velocity $[\mathrm{m} / \mathrm{s}]$ & 5.8 & 10.5 \\
\hline
\end{tabular}

\subsection{Experimental method}

The purpose of the present experiment is to investigate the influence on the cooling efficiency by the character of spray nozzle, angle of spray nozzles and a distance between spray nozzles and suction air area. Air flow velocity was set to approximately 2 meter/sec. by the blower in each experiment. Ten pieces of type A nozzles were set in the wind tunnel so that total spray flow rate was approximately $2 \mathrm{~L} / \mathrm{min}$. Each distance between one nozzle and the next was adjusted to be as equal as possible. On the other hand, a piece of nozzle was set in the case of type B nozzle because the spray flow rate was approximately $2 \mathrm{~L} / \mathrm{min}$. We paid enough attention so that spray particles do not touch the inside wall of the wind tunnel directly in each case. Pressure of nozzle feed water was set to $6.0 \mathrm{MPa}_{\text {gage. }}$. Following all pressure units are also gage. Nozzle angle was changed every 45 degrees from 0 degree, which is pointing downstream, to 360 degrees. Distance between nozzles and air suction area was set to 1 meter and to 2 meter. Only 1 meter was applied for the case of type A. 
The cooling efficiency was calculated using Eq. (1).

$\eta=\left(T_{A t m}-T_{\text {cooled }}\right) /\left(T_{A t m}-T_{W B}\right)$

Atmospheric temperature and relative humidity were set to 33 degrees centigrade and 60 percent respectively, considering summer season when supply-demand situation of electricity become tight and suction air cooling is highly expected. Air temperature after water spray was measured by eighty-one pieces of thermocouple and these values were averaged. Wet bulb temperature was measured and it was controlled to be a value of 26.4 degrees centigrade, which is calculated by inputting a temperature value of 33 degrees centigrade and a relative humidity value of 60 percent to a function of psychrometric chart, by air-conditioning units.

\subsection{Experimental results}

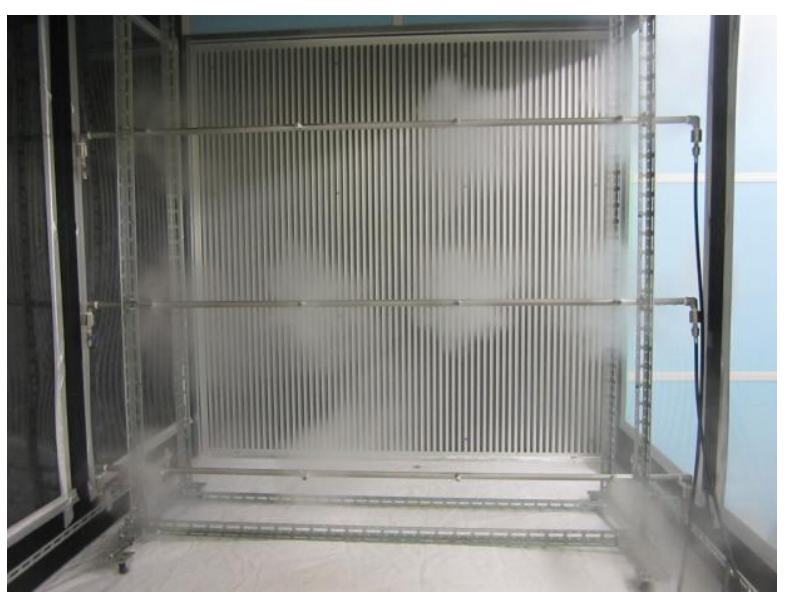

Fig. 5 Layout of type A nozzles

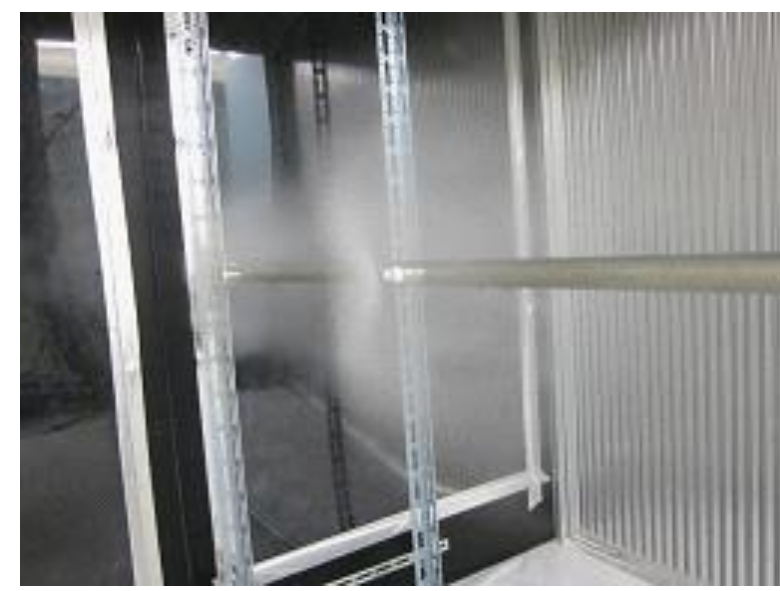

Fig. 6 Spray appearance of type A nozzles

Layout of ten type A nozzles, of which total spray flow rate was approximately $2 \mathrm{~L} / \mathrm{min}$, in the wind tunnel is shown in Fig. 5. Three pieces of nozzle are attached to the upper header, except the second position from the left. Four pieces are attached to the middle one. And three pieces are attached to the lower one, except the third position from the left. Spray appearance of the type A nozzles pointing upstream is shown in Fig. 6. It is observed that the spray appearance is spread by air flow. On the other hand, a type B nozzle was set at a cross section center of the wind tunnel when it pointed downstream and upstream. The nozzle was set at a lower/higher position when it pointed upward/downward to avoid spray particles touching the inside wall.

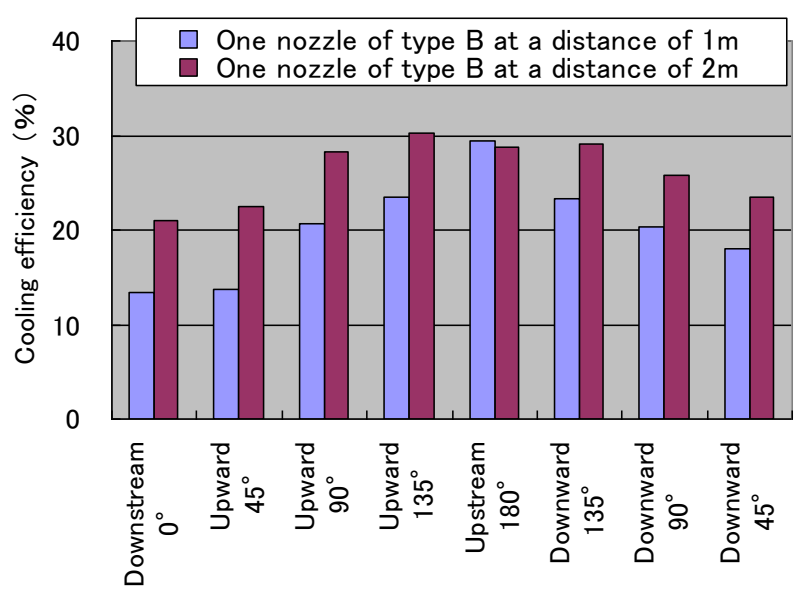

Fig. 7 Cooling efficiency of one type B nozzle

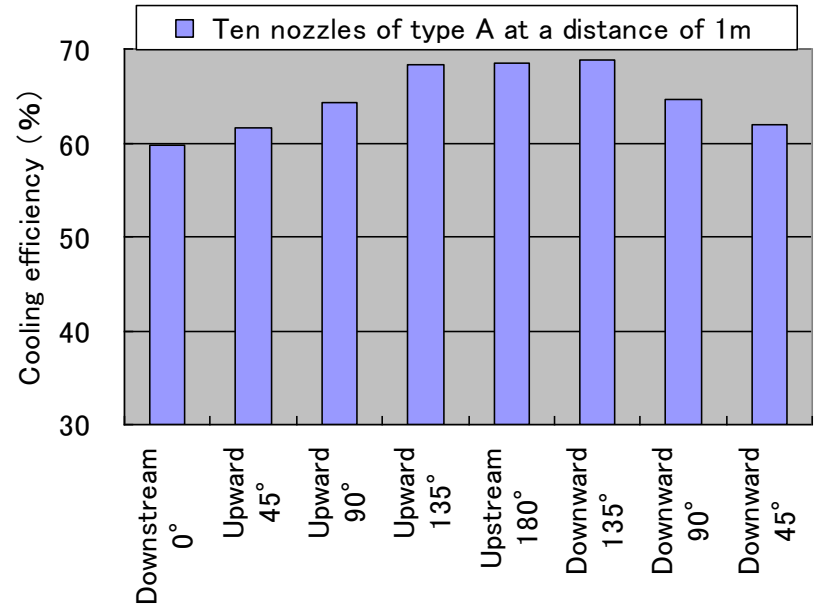

Fig. 8 Cooling efficiency of ten type A nozzles 
Cooling efficiency of one type B nozzle is shown in Fig.7. The cooling efficiency became the lowest with the nozzle angle of 0 degree, i.e. pointing downstream and became the highest with the nozzle angle of 180 degrees, i.e. pointing upstream in both the case that the nozzle distance was 1 meter and was 2 meter. It is considered that the reason is related to the fact that evaporation time, which spray particles take to reach the weather louvers after spraying, becomes longer when the spray angle is pointing upstream. It may also contribute improving cooling efficiency that evaporation area becomes larger due to spray appearance being spread.

The cooling efficiency at the nozzle distance of 2 meter was higher than that at 1 meter. The reason is also related to the evaporation time. The cooling efficiency under the condition of the nozzle distance of 2 meter and the nozzle angle of 180 degrees was a little low than the value assumed by other data. The reason can be related to the wind tunnel depth being $2.9 \mathrm{~m}$, which is not long enough to execute the experiment under the above condition.

Cooling efficiency of the ten type A nozzles is shown in Fig.8. The cooling efficiency became the lowest with the nozzle angle of 0 degree, i.e. pointing downstream and became the highest with the nozzle angle of 180 degrees, i.e. pointing upstream in the case of the nozzle distance of 1meter. The cooling efficiency of ten type A nozzles is much higher than that of one type B nozzles at each nozzle angle. The reason is related to both spray particle diameter and the evaporation space. The spray particle diameter of type A nozzles is smaller than that of type B nozzle. The evaporation space of the ten type A nozzles is larger than that of type B nozzle, because ten nozzles of type A nozzles are located with almost equal distance between one and the next in the wind tunnel.

Spray angle dependence on cooling efficiency of type B nozzle is much larger than that of type A nozzle. We think the reason is related to the evaporation time. Type B nozzle has higher spray velocity. Accordingly, the evaporation time becomes much longer when the nozzle is pointing upstream, and the time becomes much shorter when the nozzle is pointing downstream. Therefore, cooling efficiency largely changes depending on spray angle. On the other hand, type A nozzle has lower spray velocity. Accordingly, the evaporation time becomes a little longer when the nozzle is pointing upstream, and the time becomes a little shorter when the nozzle is pointing downstream. Therefore, cooling efficiency less changes depending on spray angle.

\section{CFD analysis}

\subsection{CFD analysis conditions}

Numerical analysis using computational fluid dynamics, i.e. CFD, was executed in order to investigate the cooling efficiency and temperature distribution of sprayed space depending on the nozzle angle and the nozzle structure. A commercial fluid analysis software FLUENT(V6.4) was used as a calculation code. FLUENT is a code that implicitly solves fluid velocity of three dimensions by using a finite volume method in order to discretize an analysis field, by applying the Navier-Stokes equation for compressible fluid to a dominant equation. We used FLUENT standard model, of which condition is steady state, use of energy equation considering heat transfer, phase change and radiation, and consideration of a gas composition, for the calculation model.

Table 2 Calculation conditions of CFD analysis.

\begin{tabular}{|c|c|c|c|}
\hline Nozzle & A & $\mathrm{B}$ & Note \\
\hline Width of analysis space $[\mathrm{m}]$ & 1.51 & 1.09 & \\
\hline Height of analysis space $[\mathrm{m}]$ & 2.27 & 4.34 & \\
\hline Depth of analysis space [m] & 3.00 & 3.00 & \\
\hline Distance between nozzles and exit & 2.00 & 2.00 & \\
\hline Air velocity $[\mathrm{m} / \mathrm{s}]$ & 2.3 & 2.3 & \\
\hline Inlet air temperature $\left[{ }^{\circ} \mathrm{C}\right]$ & 33 & 33 & \\
\hline Inlet air humidity [RH\%] & 60 & 60 & \\
\hline Number of nozzles & 6 & 1 & \\
\hline Total amount of water spray [L/min] & 1.22 & 1.68 & \\
\hline Total amount of water spray per cross section area $\left[\mathrm{L} / \mathrm{min} / \mathrm{m}^{2}\right]$ & 0.355 & 0.355 & The same \\
\hline
\end{tabular}

Target model shapes are produced by Gambit of mesh-producing-software as meshes of unstructured grid on three 
dimensions. The mesh number for one model is approximately fifty thousand. The physical model of the continuous phase is steady, and $\mathrm{k}-\varepsilon$ model is used for turbulent flow analysis. Boundary conditions are defined as that air flow is sucked from the exit side and each face of wall is insulated on heat transfer. The calculation of the water particle was stopped at the moment when the particle attached to the wall surface. Water particle distribution sprayed from the nozzle was simulated by the Rosin-Rammler distribution and UDF, user definition function, based on a spray particle size distribution and a velocity distribution measured by the Phase Laser Doppler Interferometer. Each water particle behavior in spray was calculated by the Lagrange equation. Evaporation of one water particle was resolved by a heat balance equation on a water particle as shown in Eq. (2) in each microscopic space. Then these were integrated into the continuous phase.

$m_{p} C_{p} \frac{d T_{p}}{d t}=h A_{p}\left(T_{\infty}-T_{p}\right)+\frac{d m_{p}}{d t} h_{f g}$

Calculation conditions of CFD analysis is shown in Table 2. Cross section area of analysis space and nozzle number were adjusted in order to set a condition that total amount of water spray per cross section area to the same for each type of spray nozzle.

\subsection{CFD analysis results}

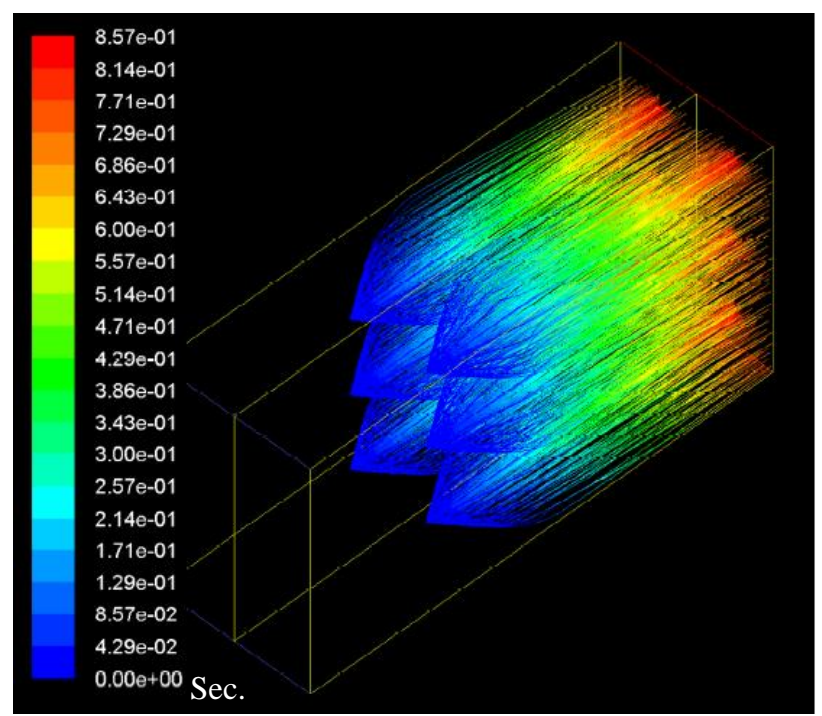

Fig. 9 Layout of six type A nozzles pointing downstream 0 degree and spray tracks

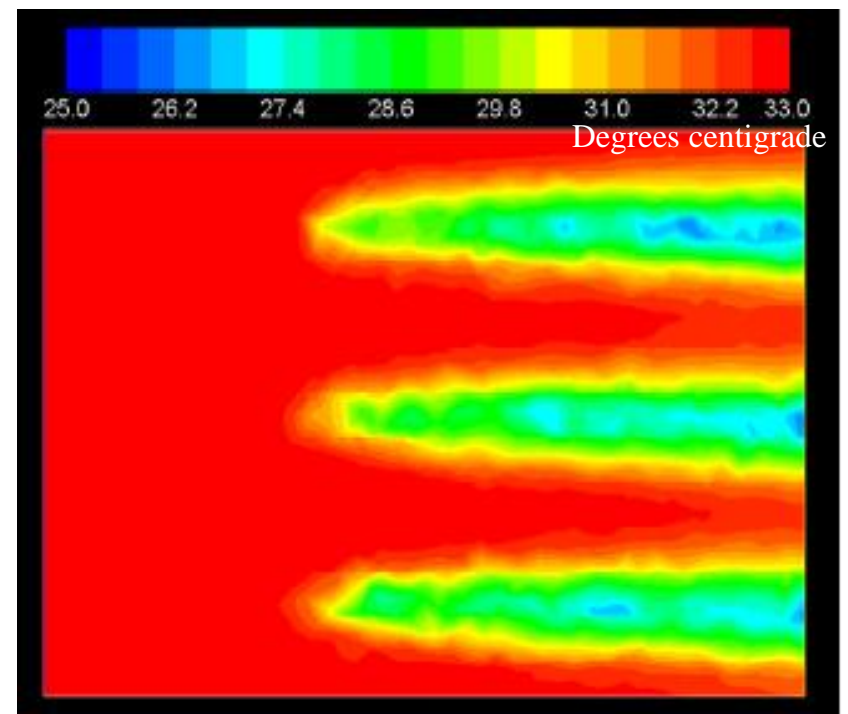

Fig. 10 Temperature distribution of side cross section of six type A nozzles pointing downstream 0 degree

Layout of six type A nozzles pointing downstream 0 degree and spray tracks are shown in Fig. 9. The nozzles were located in a cross section of 1 meter downstream from the air entrance. Each water particle distributed to go straight on after spraying. Color tone of each spray track represents staying time. Each water particle reached to the exit within 0.85 second approximately. Temperature distribution of side cross section of six type A nozzles pointing downstream 0 degree is shown in Fig. 10. And each temperature distribution of the nozzles pointing upward 90 degrees and of the nozzles pointing upward 135 degrees is shown in Fig. 11 and Fig. 12 respectively. The air flows from the left to the right in each case. The nozzles were also located in a cross section of 1 meter downstream from the air entrance in each case. It was observed that temperature of the nozzles pointing upward 135 degree is more uniform in distribution and lower than that of the nozzles pointing downstream 0 degree and that of the nozzles pointing downstream 90 degree on the whole. Namely the more nozzle angle was set, the lower the temperature became on the whole.

Temperature distribution of one type B nozzle pointing downward 90 degrees is shown in Fig. 13 and that of one type B nozzle pointing downward 135 degrees is shown in Fig 14. The nozzle was located at the position of 1 meter downstream from the air entrance in each case. It was observed that temperature of the nozzles pointing upward 135 degrees is more uniform in distribution and lower than that of the nozzles pointing downstream 90 degrees on the whole. Temperature decreasing area was very limited in each case. And temperature reduction averaged in the whole space is less than that of six type A nozzles. 


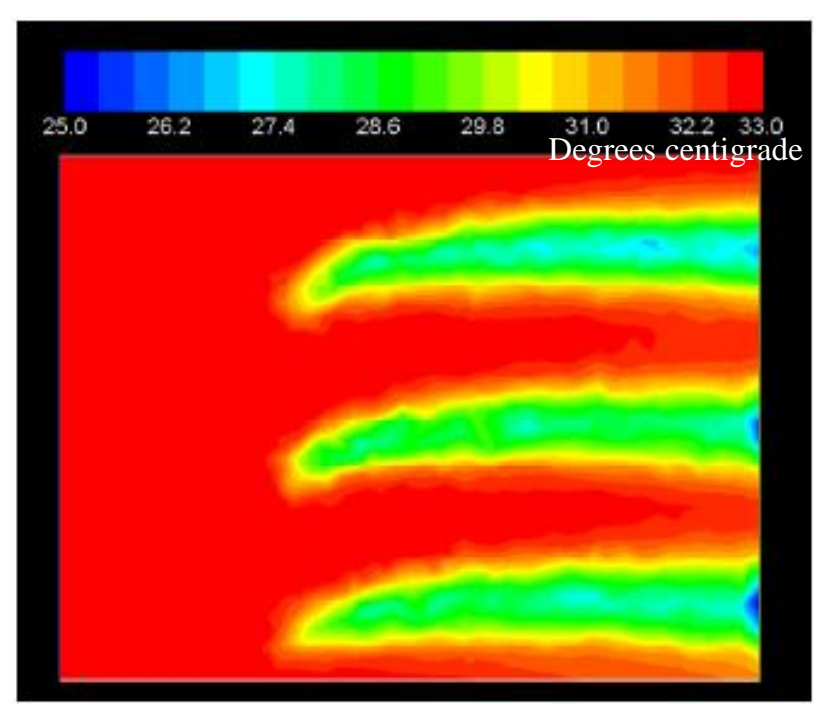

Fig. 11 Temperature distribution of side cross section of six nozzles type A pointing upward 90 degree

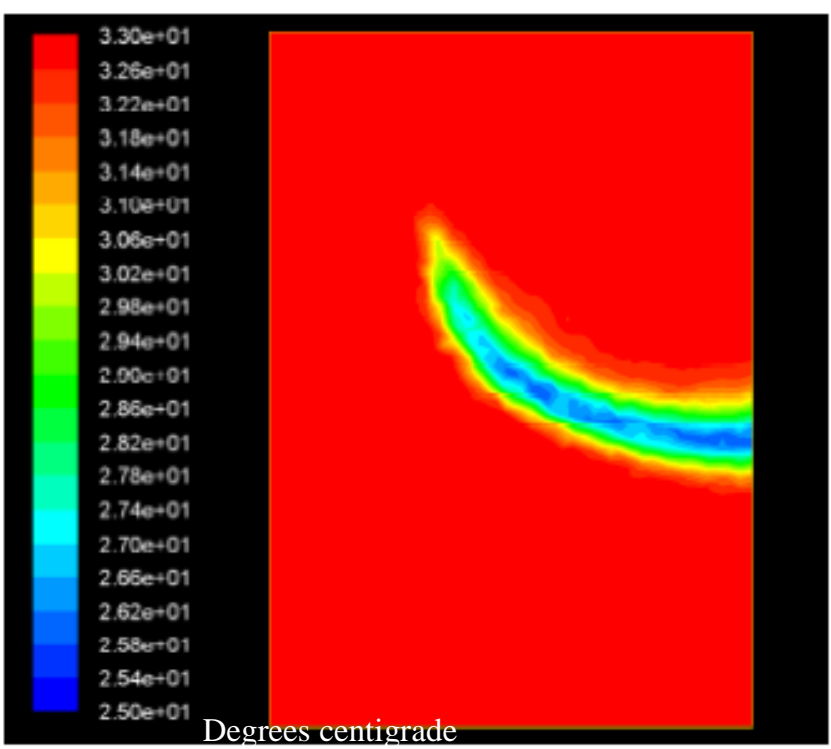

Fig. 13 Temperature distribution of side cross section of one type B nozzle pointing downward 90 degree

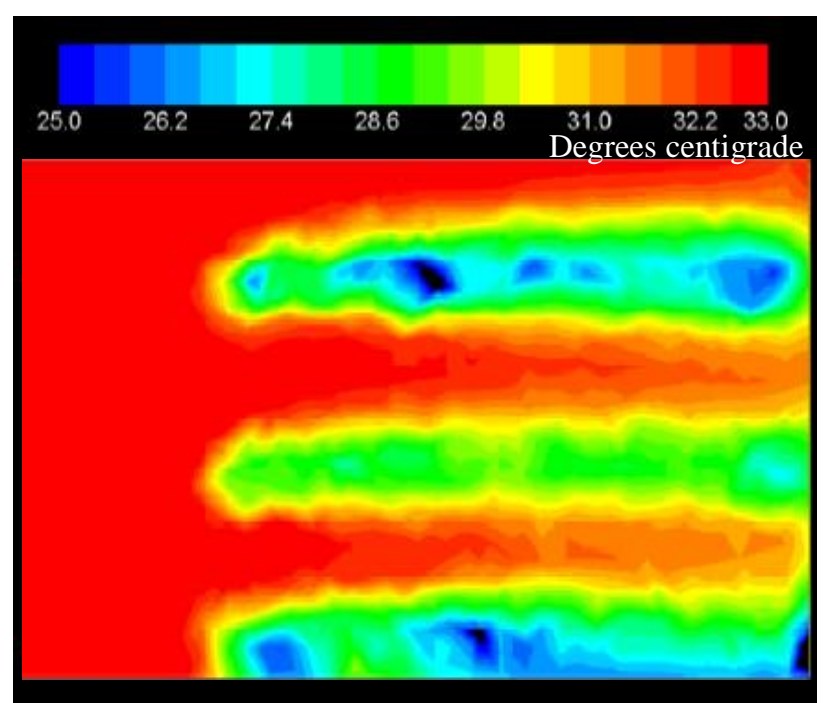

Fig. 12 Temperature distribution of side cross section of six type A nozzles pointing upward 135 degree

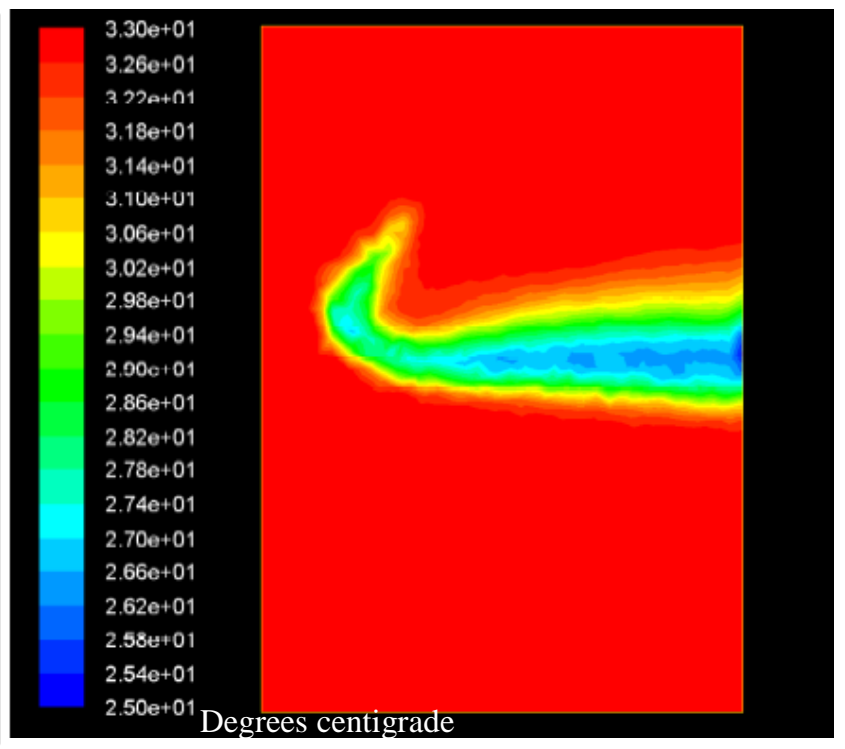

Fig. 14 Temperature distribution of side cross section of one type B nozzle pointing downward 135 degree

Table 3 Results of CFD analysis.

\begin{tabular}{|c|c|c|c|c|c|c|}
\hline Nozzle type & \multicolumn{2}{|c|}{ A } & \multicolumn{3}{c|}{ B } \\
\hline Nozzle direction & $\begin{array}{c}\text { Down } \\
\text { stream }\end{array}$ & $\begin{array}{c}\text { Up 90 } \\
\text { degree }\end{array}$ & $\begin{array}{c}\text { Up 135 } \\
\text { degree }\end{array}$ & $\begin{array}{c}\text { Down } \\
\text { stream }\end{array}$ & $\begin{array}{c}\text { Down 90 } \\
\text { degree }\end{array}$ & $\begin{array}{c}\text { Down 135 } \\
\text { degree }\end{array}$ \\
\hline Evaporated flow rate $[\mathrm{L} / \mathrm{min}]$ & 22.0 & 30.4 & 34.3 & 8.1 & 14.0 & 19.5 \\
\hline Water flow rate attached to the walls [L/min] & 0.0 & 0.0 & 0.0 & 0.0 & 0.0 & 0.0 \\
\hline Not evaporated flow rate $[\mathrm{L} / \mathrm{min}]$ & 51.2 & 42.8 & 38.9 & 92.6 & 86.7 & 81.3 \\
\hline Maximum stay time $[\mathrm{s}]$ & 0.84 & 1.02 & 1.38 & 0.53 & 0.75 & 0.81 \\
\hline Air temperature at outlet $\left[{ }^{\circ} \mathrm{C}\right]$ & 31.3 & 30.7 & 30.5 & 32.6 & 32.3 & 32.1 \\
\hline Relative humidity at outlet $\left[{ }^{\circ} \mathrm{C}\right]$ & 68.2 & 71.3 & 72.1 & 61.8 & 63.2 & 64.1 \\
\hline Reduction of air temperature $\left[{ }^{\circ} \mathrm{C}\right]$ & 1.71 & 2.28 & 2.55 & 0.39 & 0.70 & 0.87 \\
\hline
\end{tabular}


Results of CFD analysis were summarized as shown in Table 3. Temperature reduction of A type nozzle was three to four times larger than that of B type nozzle in each nozzle angle condition. And temperature reduction was the least at a nozzle angle of 0 degree, which is downstream for each type of nozzle. Then the larger as 0 degree, 90 degrees and 135 degrees the nozzle angle was in this order, the larger temperature reduction was observed for each type of nozzle. A tendency of the CFD analysis results was consistent with that of the laboratory experiments.

\subsection{Analysis of air velocity around suction air room of a combined cycle power plant by CFD analysis}

CFD analysis was conducted in order to confirm air flow velocity and air flow direction around suction air surfaces of a target $500 \mathrm{MW}$ combined cycle power plant so that the nozzle angle was adjusted adequately. FLUENT was used under the conditions of $\mathrm{k}-\varepsilon$ turbulent model and steady calculation. The conditions of suction air were set for the CFD analysis, considering the target plant, having the front suction air surface comprising of twenty-one pieces of suction air areas, i.e. seven in width and three in height, with each piece size of 2,650 $\mathrm{mm}$ in vertical length and 2,660 mm in horizontal length. Each of right side air suction surface and left one comprised nine pieces of the areas, i.e. three in width and three in height, respectively. The suction air velocity averaged on all suction air surfaces was set at $2.3 \mathrm{~m} / \mathrm{s}$. The ambient temperature was set at 33 degrees centigrade, and the humidity was set at 60 percent on average.
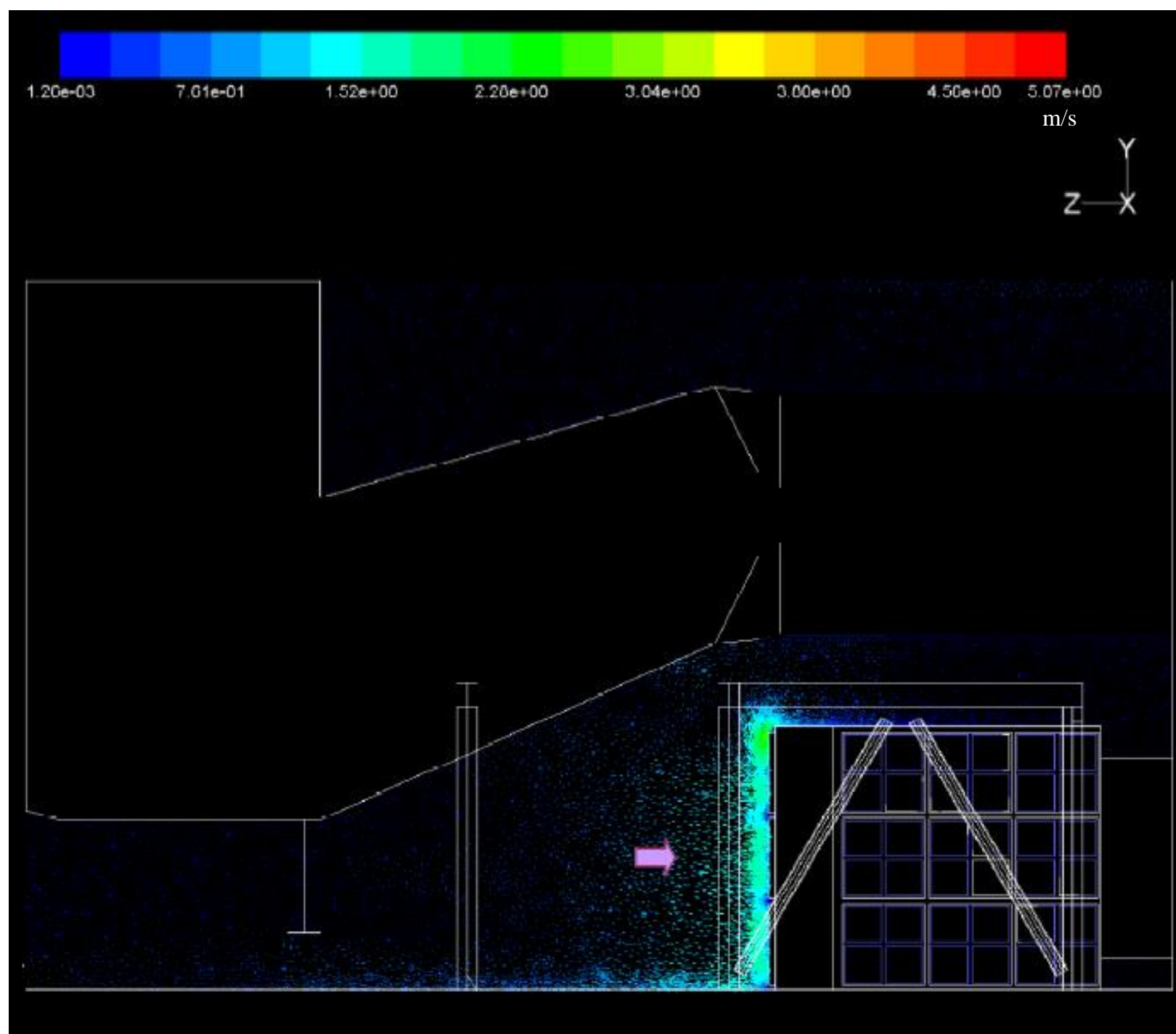

Fig. 15 Air velocity distribution of side section of a suction air room 


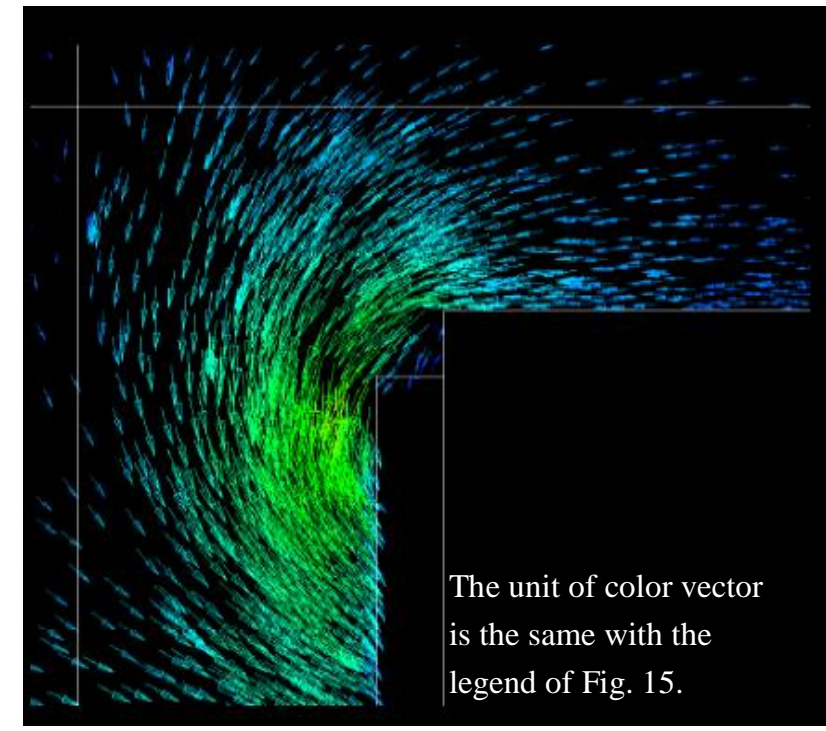

Fig. 16 Enlarged upper part of air velocity distribution of side section of a suction air room

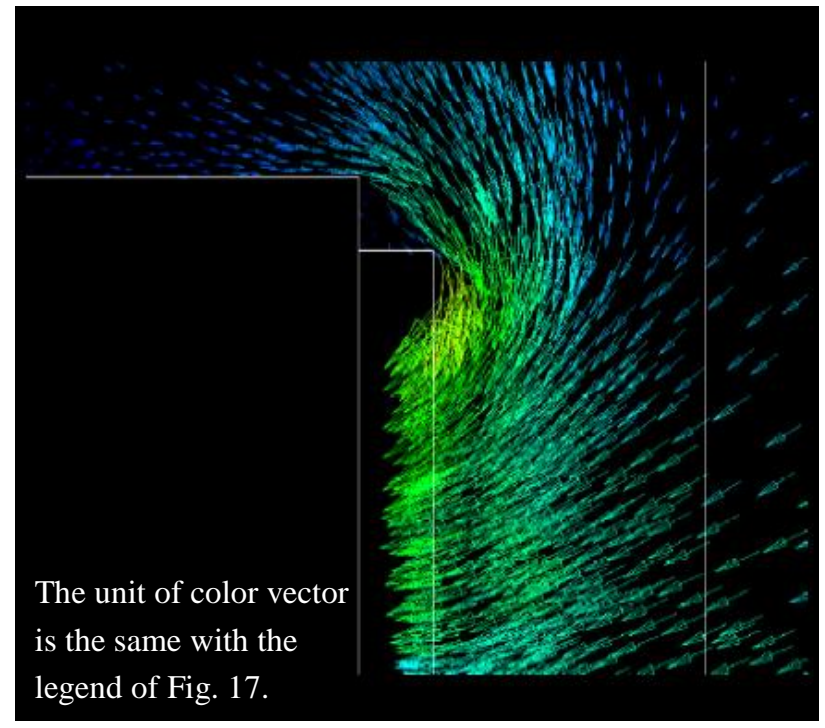

Fig. 18 Enlarged upper part of air velocity distribution of front section of the suction air room
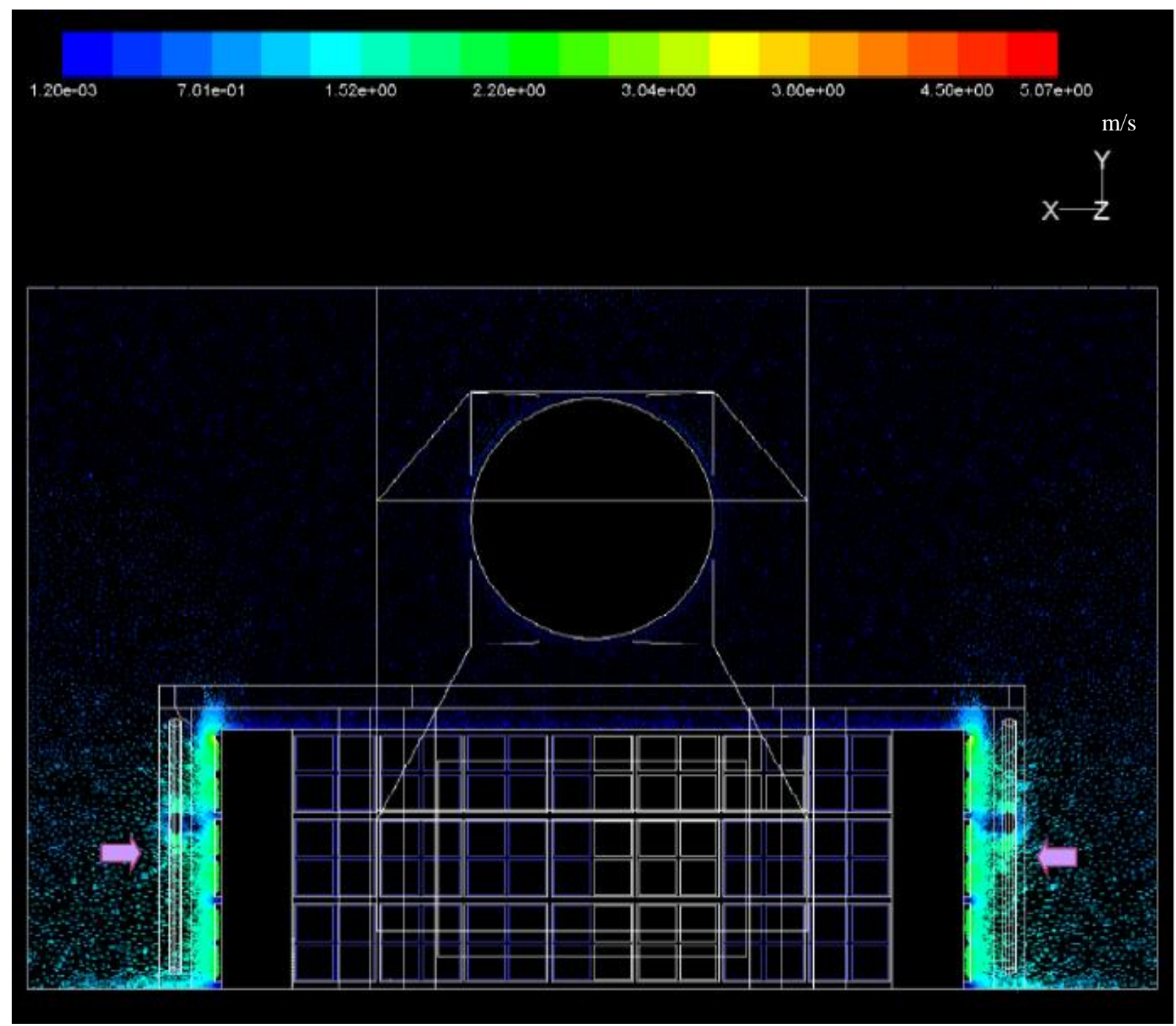

Fig. 17 Air velocity distribution of front section of the suction air room 
Results of the CFD analysis are shown in Figs. 15, 16, 17 and 18. Air velocity distribution of side section of a suction air room is shown in Fig.15. There is a gas turbine exhaust duct over the suction air room and there is a heat recovery steam generator on the left of the suction air room. Enlarged upper part of that is shown in Fig.16. It was found that the air was sucked from upper direction on the upper part of the suction air surface and the air was sucked perpendicularly on each of the middle part and the lower part of the surface.

Air velocity distribution of the front section of the suction air room is shown in Fig.17 and enlarged upper part of that is shown in Fig.18. It was found that air was sucked from upper direction of the upper part of the suction air surface and the air was sucked perpendicularly on each of the middle part and the lower part of the surface.

\section{Measurements of type B nozzles at a $380 \mathrm{MW}$ combined cycle power plant 4.1 Measurement method}

Type B nozzles are mainly used for suction air coolers of combined cycle power plants which were installed in earlier time. Each nozzle angle was set as pointing downward at the installation time. Each nozzle angle was adjusted by considering the results of the laboratory experiments and that of the CFD analysis so that the cooling efficiency became the maximum.

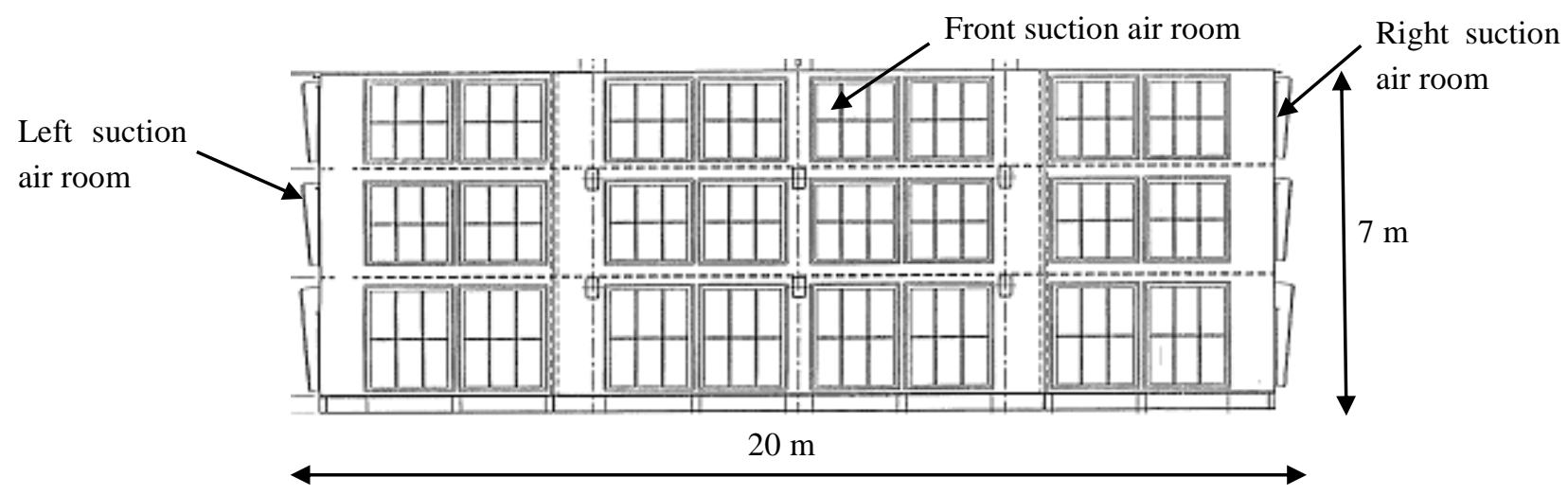

Fig. 19 Front surface of a suction air room of a combined cycle power plant

Front surface of a suction air room of a combined cycle power plant is shown in Fig. 19. The suction air room has a structure of three floors. The height is approximately 7 meter and the width is approximately 20 meter. A right suction air room and the left one were located on both side of the front one respectively. Each height is the same as the front one which is approximately 7 meter and each width is approximately 8 meter. Air velocity averaged on all suction air room surfaces is approximately 2 meter/sec. at a full load of $380 \mathrm{MW}$. One water spray header was installed on each floor of each suction air room surface, i.e. three water spray headers were set in total. Eighty-four pieces of the spray nozzles of were set in all. Spray pressure was set to $6.0 \mathrm{MPa}$ and the distance between the nozzles and each of the suction air surfaces was approximately 1 meter.

Each nozzle angle was basically adjusted to point upstream considering the air velocity distribution around suction air room on the basis of CFD analysis results. Namely each nozzle angle at upper part was adjusted to point upper direction and each nozzle angle at middle part and at lower part was adjusted to point horizontal direction. Then nozzle angle was adjusted at each section considering suction air velocity at the working plant so that the spray could spread larger with visual inspections as shown in Fig. 20.

Eighty-four pieces of thermocouples were uniformly installed in the front suction air room, which is with equipped weather louvers upstream for spray and rain to be eliminated, in order to measure the cooling efficiency using Eq. (1).

The measurement conditions of the cooling efficiency are mentioned as follows.

(1) All nozzles are pointing downward, and spray pressure is 6.0 MPa.

(2) Nozzles of left quarter surface of front air suction room and those of right quarter one are pointing upstream and those of middle two quarters one are pointing downward, and spray pressure is 6.0 $\mathrm{MPa}$.

(3) All nozzles are pointing upstream, and spray pressure is 5.7 MPa.

(4) All nozzles are pointing upstream, and spray pressure is $6.0 \mathrm{MPa}$. 


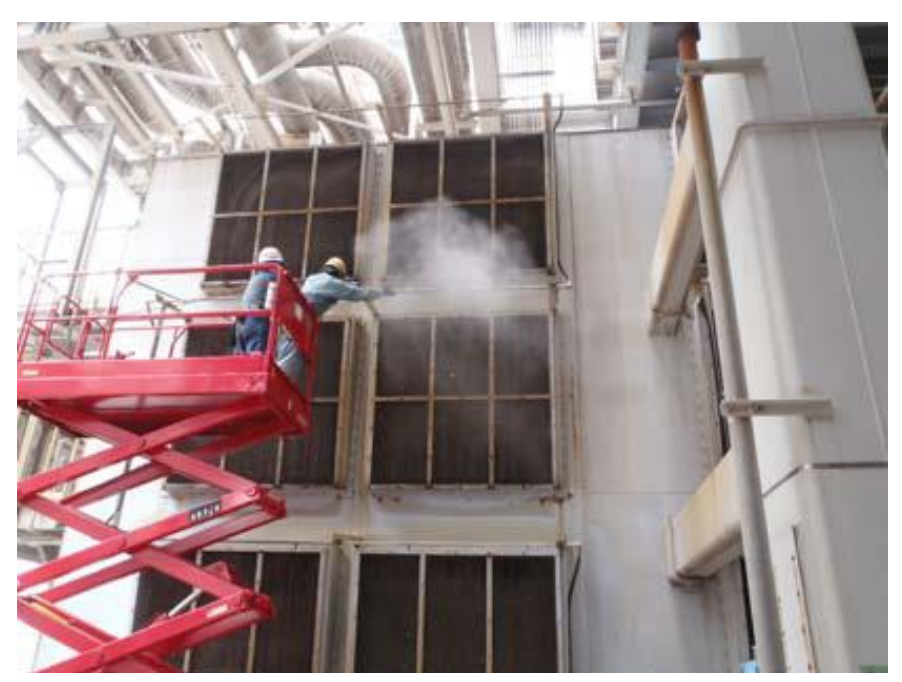

Fig. 20 Adjustment of nozzle angle at each section

\subsection{Measurement results}

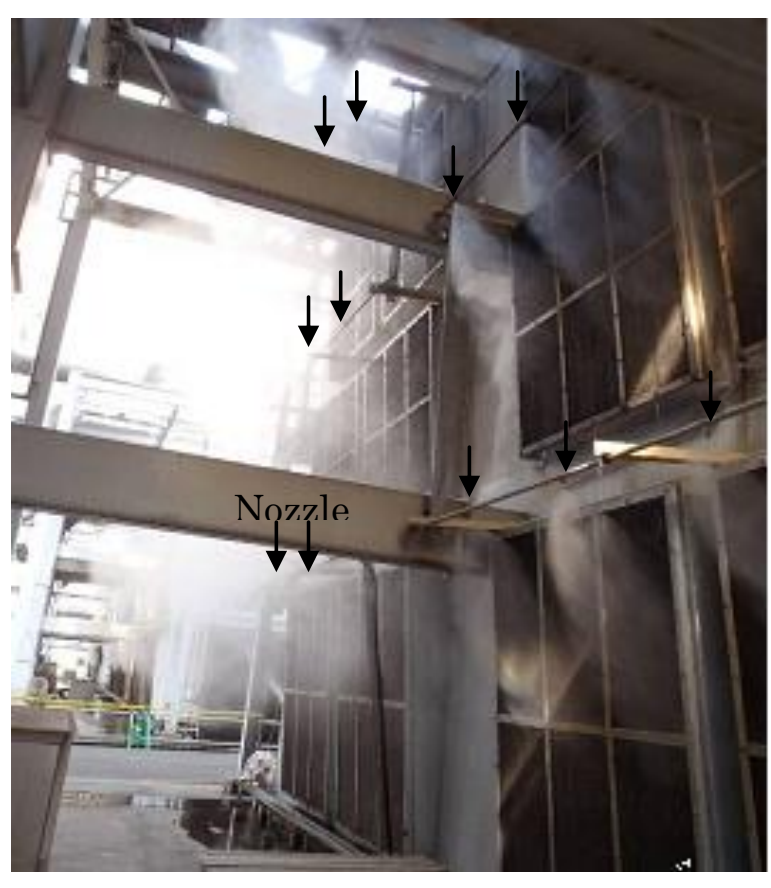

Fig. 21 Nozzles of adjusted angle (left) and unadjusted (right)

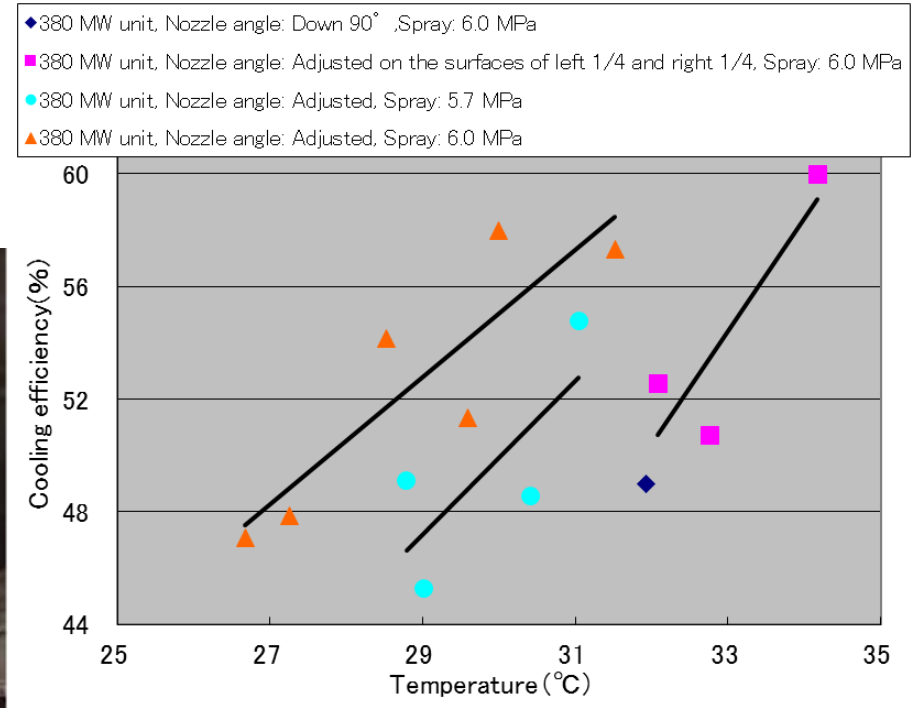

Fig. 22 Measurement results of cooling efficiency

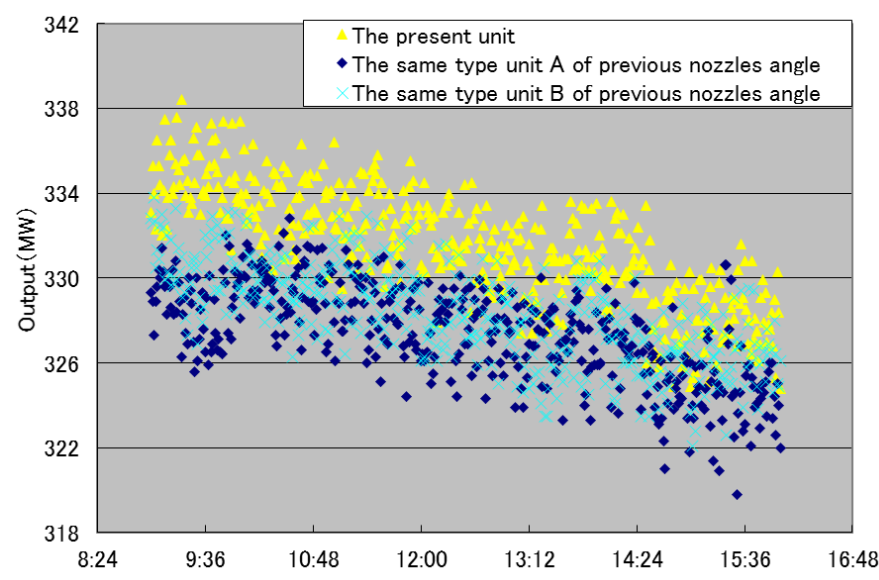

Fig. 23 Output comparison among the same type units 
Spraying nozzles of the front suction air room are shown in Fig. 21. Nozzles of adjusted angle are on the left hand side, and those of unadjusted are on the right hand side. Arrows represent nozzle positions. It can be observed that spray from the adjusted nozzles widely spread to the air space and be sucked to the suction air room slowly and that from the unadjusted nozzles was hardly spread and sucked to the suction air room directly.

Measurement results of cooling efficiency at the $380 \mathrm{MW}$ unit are shown in Fig. 22. One scale on the vertical axis is four percent. The horizontal axis represents atmospheric temperature near the suction air room, which is not affected by water spray. Relative humidity of air was between 50 percent and 70 percent in each measurement. The cooling efficiency measured under each condition has positive temperature dependence respectively. The cooling efficiency of the condition (1) of unadjusted nozzle angle is the lowest value, considering the dependence. The efficiency of the condition (2) of the left quarter nozzles and the right quarter one being adjusted is the second lower value. The efficiency of the condition (3) of all nozzles being adjusted with spray pressure of 5.7 MPa is the third lower value. The efficiency of the condition (4) of all nozzles being adjusted with spray pressure of 6.0 MPa is the highest value. Namely it was found that the better the nozzle angle and the nozzle pressure were, the higher the cooling efficiency was. The efficiency of all nozzles being adjusted with spray pressure of 6.0 MPa was 10 percent higher than that of unadjusted nozzles. Then temperature reduction of all nozzles being adjusted with spray pressure of $6.0 \mathrm{MPa}$ is 0.7 degrees centigrade more than that of unadjusted nozzles.

Output comparison among the same type units is shown in Fig. 23. One scale on the vertical axis is 2 MW. The horizontal axis represents time from the morning to the evening in summer season. Each unit was working with full load. It is observed that each output is decreasing with atmospheric temperature increase. Output of the present unit with adjusted nozzle angle is plotted as triangle dots and each output of the unit A and the unit B with unadjusted nozzle angle is plotted as round dots and as cross dots respectively. It was confirmed that the present unit output was 3 to 4 MW larger than the other unit output. However, the output difference may be possible to include the unit characteristic difference and other factors. The present unit output before adjusting nozzle angle was approximately $1 \mathrm{MW}$ larger than that of the other unit output. The effect of adjusting nozzle angle can be estimated to be 2 to $3 \mathrm{MW}$, considering the influence.

\section{Measurements of type A nozzles at a $500 \mathrm{MW}$ combined cycle power plant 5.1 Measurement method}

Type A nozzles are mainly used for suction air coolers of working combined cycle power plants which were installed recently. Each nozzle angle was set pointing downstream at the installation time. Each nozzle angle was adjusted to point upstream by considering the results of the laboratory experiments and that of the CFD analysis so that cooling efficiency became the maximum. Namely each nozzle angle at upper part was adjusted to point upper direction and each nozzle angle at middle part and at lower part was adjusted to point horizontal direction.

The suction air room has a structure of three surfaces, of which each consists of three floors. A right suction air room and the left one were located on both side of the front one respectively. Air velocity averaged on all suction air room surfaces was approximately 2 meter/sec at a full load of $500 \mathrm{MW}$. Two water spray headers were set on each floor of each suction air room surface, i.e. six water spray headers were set in total. 492 pieces of the spray nozzle were set in all. Spray pressure was 6.0 MPa and the distance between the nozzles and each of the suction air surfaces was approximately 1 meter.

158 pieces of thermocouples were uniformly installed in the front suction air room, in right one and in left one which are equipped with weather louvers upstream for spray and rain to be eliminated. The measurements were conducted before and after adjusting nozzle angle, in order to obtain cooling efficiency using Eq. (1).

\subsection{Measurement results}

Nozzles of unadjusted angle pointing downstream are shown in Fig. 24 and nozzles of adjusted angle pointing upstream in Fig. 25. It was observed that spray from unadjusted nozzles was not spread and sucked to the suction air room straightly with a thin conical shape. On the other hand, spray from adjusted nozzles was spread widely and sucked to the suction air room slowly with a thick cloud cylinder shape.

Measurement results of cooling efficiency at the $500 \mathrm{MW}$ unit are shown in Fig. 26. The horizontal axis represents atmospheric temperature near the suction air room, which is not affected by water spray. Relative humidity of unadjusted 
nozzle measurement was 25 percent and relative humidity of adjusted nozzle measurement was 38 percent when atmospheric temperature was 18 degrees centigrade and that was 71 percent when atmospheric temperature was 29 degrees centigrade. The measurement results of the $380 \mathrm{MW}$ unit are also shown on it as a reference. The cooling efficiency of adjusted nozzles has positive temperature dependence. It was found that the cooling efficiency of adjusted nozzles was several percent higher than that of unadjusted nozzles, considering the dependence. However, many condition data were not obtained at present measurement. Accordingly, it may be difficult to evaluate quantitative difference between the efficiency of adjusted nozzles and that of unadjusted one in this case.

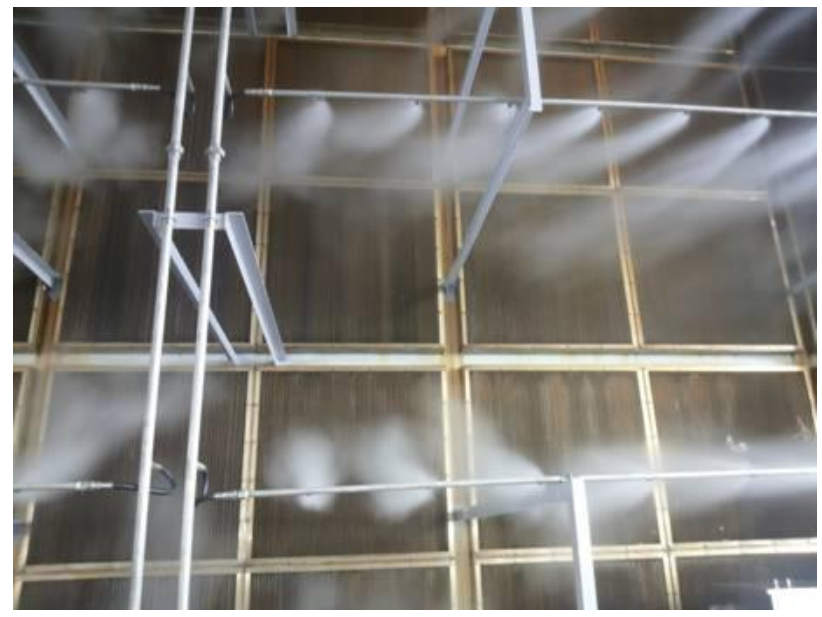

Fig. 24 Nozzles of unadjusted (straight, downstream)

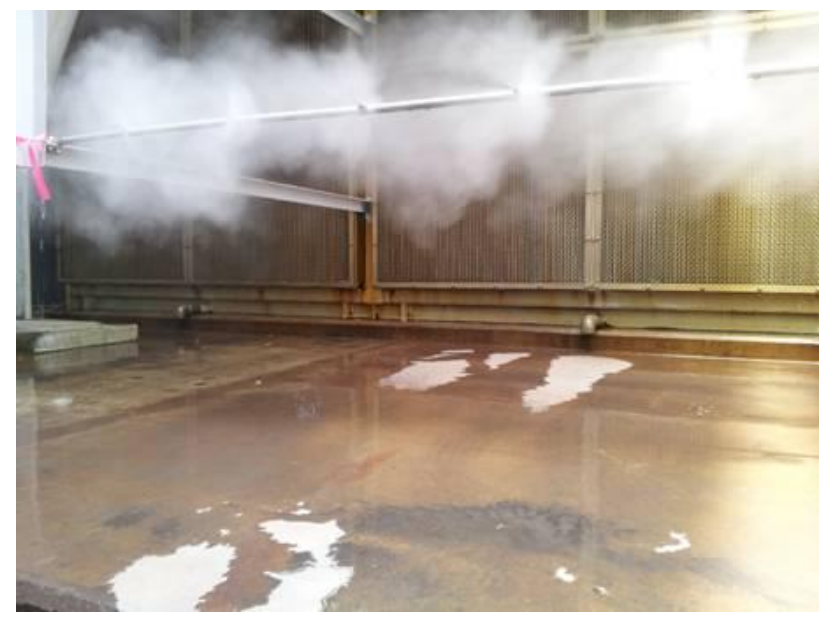

Fig. 25 Nozzles of adjusted angle (upstream)

The cooling efficiency of type A nozzle at the $500 \mathrm{MW}$ unit was higher than that of type B at 380 MW unit. The tendency is consistent with the results of the laboratory experiments and that of the CFD analysis. And the temperature dependence on the cooling efficiency of type A nozzles at the $500 \mathrm{MW}$ unit was almost equal to that of type B one measured at the $380 \mathrm{MW}$ unit.

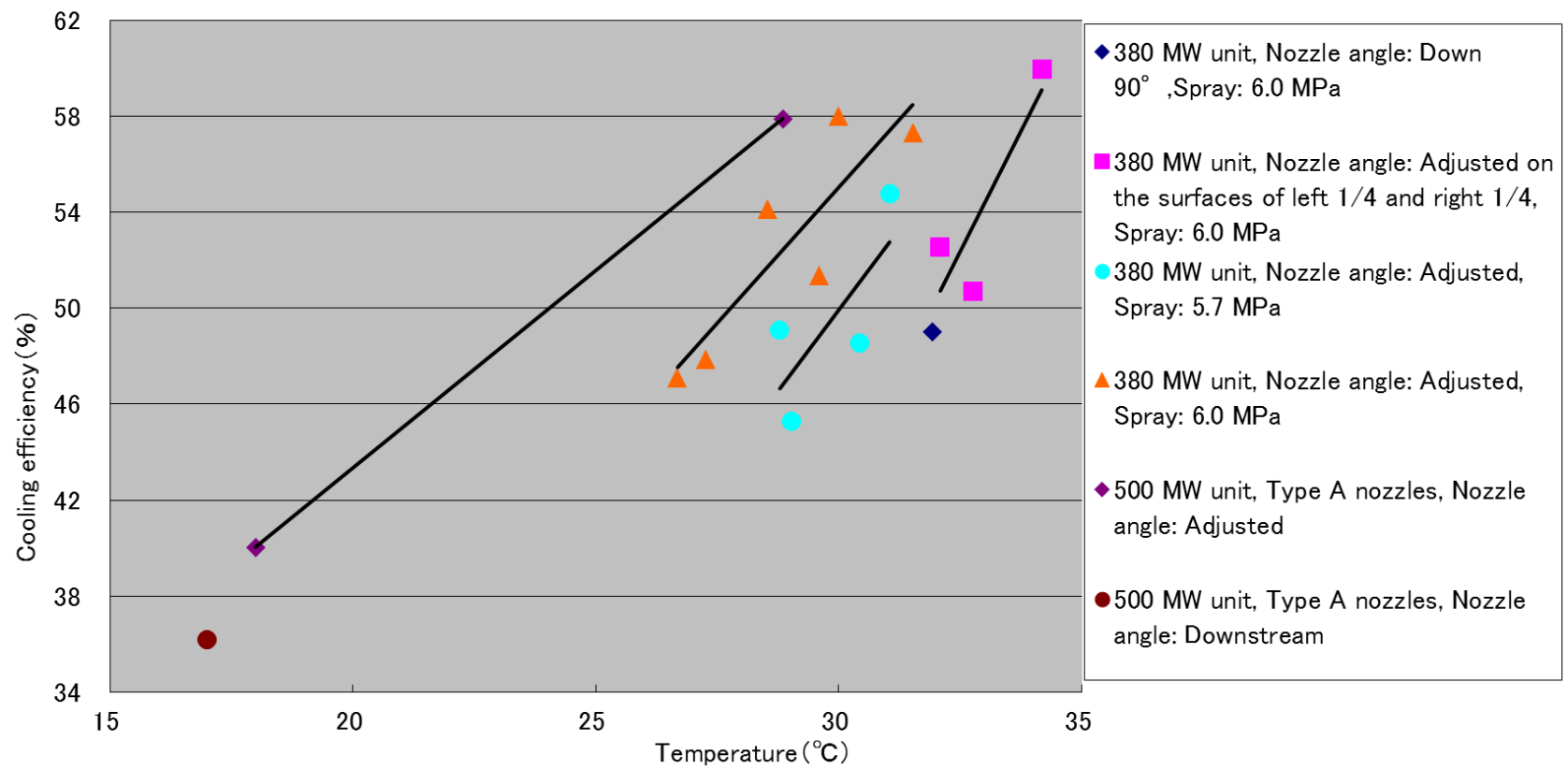

Fig. 26 Measurement results of cooling efficiency

\section{Conclusions}


Laboratory experiments of suction air cooling using two kinds of spray nozzles were conducted in order to improve cooling efficiency. The experimental conditions were set by considering summer season circumstance of working combined cycle power plants. As a result, the efficiency became the highest with nozzles pointing upstream in both the case of type A nozzles of which the nozzle distance was each of 1 meter and 2 meter and the case of type B nozzles of which the nozzle distance was 1 meter. The tendency was also confirmed by the finite volume analysis using a CFD program. This method was examined at both a working combined cycle power plant of $380 \mathrm{MW}$ and that of $500 \mathrm{MW}$ on trial. Temperature of cooled air was measured using a number of thermocouples in the suction air room at each plant. Consequently, it was observed that the cooling efficiency was improved by ten percent and several percent respectively, and the plant output was increased by approximately $2 \mathrm{MW}$ at the $380 \mathrm{MW}$ plant.

\section{Acknowledgement}

The authors would like to express their gratitude to Shiro Nakai and Yoshihiko Tanigawa of Ikeuchi Co., LTD. for their valuable corporations for the numerical analysis using computational fluid dynamics.

\section{References}

Kahn, J. R., Wang, T. and Chaker, M., Investigating of Cooling Effectiveness of Gas Turbine Inlet Fogging Location Relative to the Silencer, Transactions of the ASME, Journal of Engineering for Gas turbine and Power, Vol. 134 (2012), pp. 022001-9.

Umezawa, S., Output increase of conventional thermal plants by the method of feed water bypassing feed water heaters, Proceedings of the International Conference on Power Engineering-13(ICOPE-13)(2013), Paper No. 189.

Umezawa, S., Output increase of conventional thermal plants by the method of feed water bypassing feed water heaters, Mechanical Engineering Journal, Vol.1, No.5 (2014), pp.1-10.

Umezawa, S., Tanaka, K., Improvement of a method cooling suction air of combined cycle power plants using water spray and applications to working plants, Proceedings of annual meeting of the Japan Society of Mechanical Engineers (2014), Paper No. S0820102(in Japanese). 